\title{
The Danish nationwide clinical register for patients with rheumatoid arthritis: DANBIO
}

This article was published in the following Dove Press journal:

Clinical Epidemiology

25 October 2016

Number of times this article has been viewed

\author{
Else Helene Ibfelt ${ }^{1}$ \\ Dorte Vendelbo Jensen ${ }^{2,3}$ \\ Merete Lund Hetland ${ }^{2,4}$ \\ 'Registry Support Centre (East), \\ Epidemiology and Biostatistics, \\ Research Centre for Prevention \\ and Health, Rigshospitalet, Glostrup \\ University Hospital, ${ }^{2}$ DANBIO \\ Registry and Copenhagen Center \\ for Arthritis Research, Center for \\ Rheumatology and Spine Diseases, \\ Centre of Head and Orthopedics, \\ Rigshospitalet, Glostrup, ${ }^{3}$ Department \\ of Rheumatology, Herlev and Gentofte \\ University Hospital, Hellerup, \\ ${ }^{4}$ Department of Clinical Medicine, \\ Faculty of Health and Medical \\ Sciences, University of Copenhagen, \\ Copenhagen, Denmark
}

Introduction: DANBIO is a research register and a data source for rheumatologic diseases (rheumatoid arthritis [RA], axial spondyloarthritis, and psoriatic arthritis) for monitoring clinical quality at the national, regional, and hospital levels.

Study population: The register includes patients with rheumatologic diseases who are treated at a hospital or a private rheumatologic clinic. Registration is mandatory for all patients with RA regardless of treatment and also for patients with other diagnoses if treated with biological disease-modifying antirheumatic drugs. Since 2006, the registration has been done electronically, including patient-reported outcome measures registered electronically by the patients with the use of touch screens.

Main variables: Core variables such as diagnosis, year of diagnosis, age, and sex are registered at the beginning. Data entered at later visits included the following: patient-reported outcomes for disease activity, pain, fatigue, functional status, and physician-reported objective measures of disease activity, treatment, C-reactive protein, and, when indicated, imaging. For subgroups of patients, the variables such as quality of life, sociodemographic factors, lifestyle, and comorbidity are also registered.

Descriptive data: The DANBIO cohort comprised 26,000 patients with RA, 3,200 patients with axial spondyloarthritis, and 6,200 patients with psoriatic arthritis in 2015. DANBIO has high nationwide coverage and completeness on key data variables. More than 60 original papers as well as annual reports of clinical quality (since 2005) have been published.

Conclusion: DANBIO is a powerful register for research in rheumatologic diseases and furthermore serves as a Clinical Quality Register with the aim of monitoring treatment quality in patients with RA in Denmark.

Keywords: rheumatoid arthritis, axial spondyloarthritis, psoriatic arthritis, DANBIO register clinical quality, epidemiology

\section{Introduction}

The database, DANBIO, is a nationwide, Danish register for research use in rheumatologic diseases such as rheumatoid arthritis (RA), axial spondyloarthritis (Ax SpA), and psoriatic arthritis (PsA). It also serves as a clinical database that monitors clinical quality of treatment by the use of selected quality indicators for patients with RA in Denmark.

\section{Study population and data collection}

Up to the year 2000, no routine-based nationwide reporting of patients with RA existed in Denmark, and patient files rarely comprised quantitative patient-reported outcome submit your manuscript | www.dovepress.com

Dovepress

http://dx.doi.org/10.2147/CLEP.S99490
Clinical Epidemiology 2016:8 737-742 (Thematic series on clinical quality databases in Denmark) 737 (c) (i) (5) 2016 lbfelt et al. This work is published and licensed by Dove Medical Press Limited. The full terms of this license are available at https://www.dovepress.com/terms.php (c) $\mathrm{BY}$ and incorporate the Creative Commons Attribution - Non Commercial (unported, v3.0) License (http://creativecommons.org/licenses/by-nc/3.0/). By accessing the work you hereby accept the Terms. Non-commercial uses of the work are permitted without any further permission from Dove Medical Press Limited, provided the work is properly attributed. For permission for commercial use of this work, please see paragraphs 4.2 and 5 of our Terms (https://www.dovepress.com/terms.php 
data. The introduction of new biological disease-modifying antirheumatic drugs (bDMARDs) triggered the formation of a nationwide voluntary register, which aimed to survey indications for treatment, efficacy, and adverse events in rheumatologic patients who received biological therapies in routine care.

In the beginning, data were collected on paper forms, which were subsequently scanned into the register at the DANBIO office. ${ }^{1}$ In 2006, an online version of DANBIO was introduced, and the aims were extended to include patients regardless of treatment and also to collect patient-reported outcomes regarding, eg disability, pain, lifestyle, and quality of life by the use of dedicated touch screens in the waiting room (Figure 1). This is routinely done before consultation with the doctor, and the information from the touch screen is available during the consultation. DANBIO has been approved by the National Board of Health as a Clinical Quality Register, and since 2006, reporting to the register has been mandatory. For clinical quality registers, the usual requirement for obtaining an informed patient consent before registration is not needed. Only rarely do patients object to be included in the register, and in these cases, it is up to the physician to decide whether to register the patient or not.

$\mathrm{RA}, \mathrm{Ax} \mathrm{SpA}$, and PsA are chronic diseases that require lifelong monitoring and treatment. A patient is therefore reported to the database at the time of diagnosis, referral to specialized treatment, including biological therapy at the hospital, or in a private rheumatologic clinic. At the first registration, the diagnosis, date of diagnosis, age, sex, and previous medical treatment are registered. At later visits, and at least once yearly, information regarding patient's disease activity (including pain and functional status) is collected

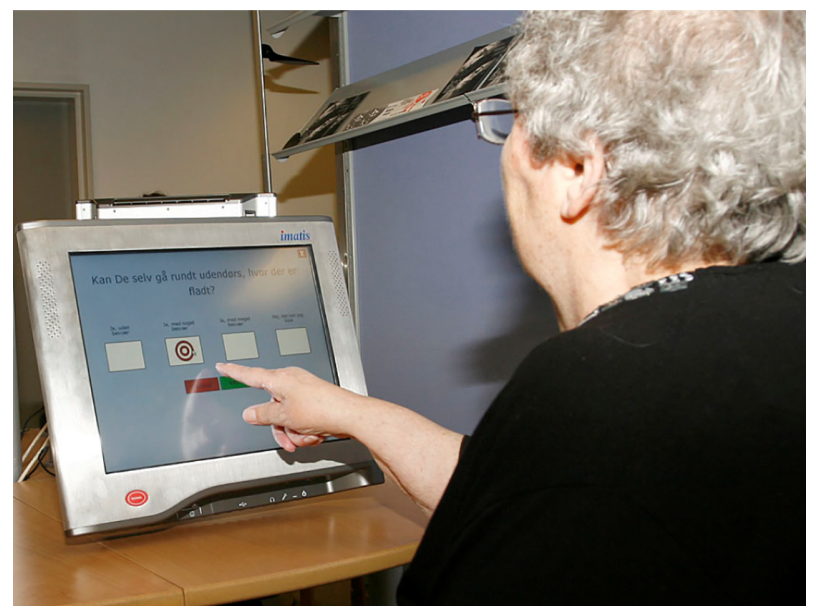

Figure I A patient using the touch screen. Note: Reprinted with permission from DANBIO. via touch screens, and objective measures (eg, swollen and tender joint counts, C-reactive protein) are entered by the physician.

The patient groups with Ax SpA and PsA are not included at the moment in the National Clinical Quality Program, and therefore reporting is only mandatory for patients with RA and for the other patient groups only when treated with bDMARDs. In the beginning of 2015, the DANBIO cohort comprised 26,000 patients with RA, 3,200 patients with Ax SpA, and 6,200 patients with PsA treated with conventional synthetic DMARDs and/or bDMARDs.

\section{Main variables}

Table 1 gives the key variables of the register. Some variables are collected via touch screens (patient-reported outcome measures [PROMs]), and others are entered by the physician.

The use of touch screens for data collection has been validated to perform equally well as paper forms (Figure 1). ${ }^{2}$ The variables are collected in a standardized format, often using tick boxes, which have been shown to have a high validity. ${ }^{1}$ Figure 2 shows the scoreboard for entering and reviewing individual patient data. In connection with ie, queries from DANBIO and research projects, the departments fill in missing data by checking against the hospital patient records.

The completeness of data is generally high (ie, $96 \%, 93 \%$, $83 \%, 90 \%$, and $93 \%$ for information on the name of the treating doctor, diagnosis, year of diagnosis, DAS28, and HAQ, respectively). National coverage of DANBIO is assessed annually in two ways: for patients in biological treatment by comparing to those registered in the patient record systems of each rheumatologic department (94\% in 2013) and by

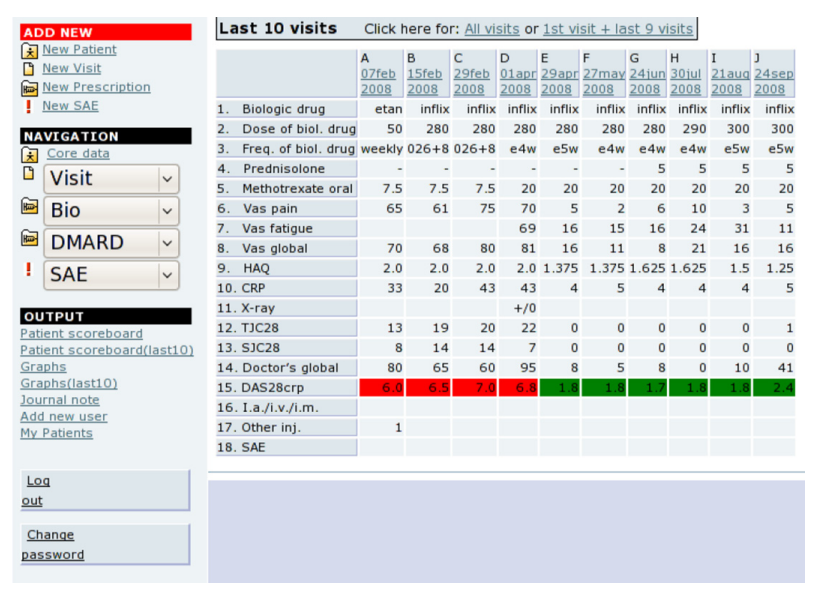

Figure 2 Overview of patient data.

Note: Reprinted with permission from DANBIO. 
Table I Key variables in the DANBIO register

\begin{tabular}{lll}
\hline Type of variable & Name of variable & Disease group \\
\hline $\begin{array}{l}\text { Baseline variables } \\
\text { Sociodemographic factors }\end{array}$ & & \\
& Age & \\
& Sex & RA, Ax SpA, PsA \\
PROMs & Marital status & RA, Ax SpA, PsA \\
PROMs & Educational level & RA, Ax SpA, PsA \\
Disease-related variables & & \\
& Diagnosis & RA, Ax SpA, PsA \\
& Year of diagnosis & RA, Ax SpA, PsA \\
& Previous DMARD & \\
& treatment & \\
& Anti-CCP and IgM-RF & RA \\
& status ( \pm ) & \\
& MRI & Ax SpA \\
Health behavioral factors (once a year) & \\
PROMs & Tobacco use & RA, Ax SpA, PsA \\
PROMs & Alcohol consumption & RA, Ax SpA, PsA \\
PROMs & Physical activity & RA, Ax SpA, PsA \\
PROMs & EQ-5D & RA, Ax SpA, PsA \\
& X-ray status (when & RA, PsA \\
& indicated) &
\end{tabular}

Variables at each visit

Disease activity measures

\begin{tabular}{|c|c|c|}
\hline & DAS28 ${ }^{a}$ & RA, PsA \\
\hline & Tender joints count & RA, PsA \\
\hline & Swollen joints count & RA, PsA \\
\hline PROMs & VAS for pain & $R A, A \times S p A, P s A$ \\
\hline PROMs & VAS for fatigue & $R A, A \times S p A, P s A$ \\
\hline \multirow[t]{2}{*}{ PROMs } & VAS for patient's global & $R A, A x \operatorname{SpA}, P s A$ \\
\hline & VAS for physician's global & $R A, A x \operatorname{SpA}, P_{s} A$ \\
\hline \multirow[t]{2}{*}{ PROMs } & Health Assessment & RA, PsA \\
\hline & Questionnaire $(\mathrm{HAQ})^{\mathrm{b}}$ & \\
\hline PROMs & BASDAl $^{\mathrm{c}}$ & $A \times S p A$ \\
\hline \multirow[t]{3}{*}{ PROMs } & $\mathrm{BASFI}^{\mathrm{d}}$ & $\mathrm{A} \times \mathrm{SpA}$ \\
\hline & BASMle & $\mathrm{A} \times \mathrm{SpA}$ \\
\hline & Serum CRP & $R A, A x \operatorname{SpA}, \operatorname{Ps} A$ \\
\hline Current treatment & NSAID & $A \times S p A$ \\
\hline \multirow{3}{*}{ (start date, dose, interval) } & csDMARDs & $R A, A \times S p A, P s A$ \\
\hline & bDMARDs & $R A, A x \operatorname{SpA}, \mathrm{Ps} A$ \\
\hline & Glucocorticoids & $R A, A x \operatorname{SpA}, \mathrm{Ps} A$ \\
\hline \multicolumn{3}{|c|}{ Variables at treatment termination } \\
\hline & $\begin{array}{l}\text { Relevant disease activity } \\
\text { measures }\end{array}$ & $R A, A x \operatorname{SpA}, \mathrm{Ps} A$ \\
\hline & $\begin{array}{l}\text { Date and reason for } \\
\text { withdrawal }\end{array}$ & $R A, A \times S p A, P s A$ \\
\hline \multicolumn{3}{|l|}{ Adverse effect variables } \\
\hline & Serious/not serious & $R A, A x S p A, P s A$ \\
\hline \multirow{2}{*}{\multicolumn{3}{|c|}{ 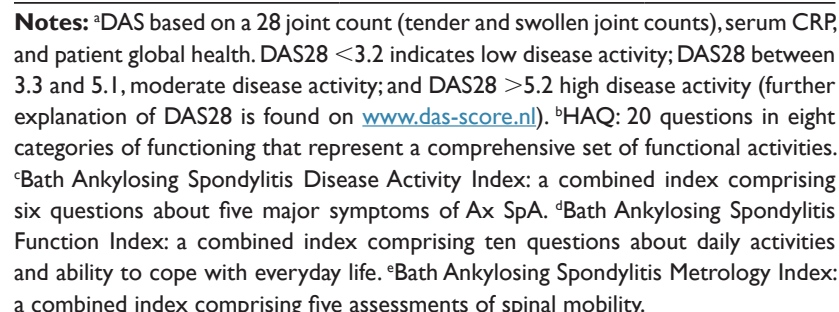 }} \\
\hline & & \\
\hline \multirow{3}{*}{\multicolumn{3}{|c|}{$\begin{array}{l}\text { Abbreviations: Ax SpA, axial spondyloarthritis; DMARD, disease-modifying antirheu- } \\
\text { matic drugs; bDMARDs, biological disease-modifying antirheumatic drugs; CRP, } \\
\text { C-reactiveprotein;csDMARDs,conventional synthetic disease-modifying antirheumatic } \\
\text { drugs; DAS, disease activity score; HAQ, Health Assessment Questionnaire; NSAIDs, } \\
\text { nonsteroid anti-inflammatory drugs; PROMs, patient-reported outcome measures; }\end{array}$}} \\
\hline & & \\
\hline & & \\
\hline \multicolumn{3}{|c|}{$\begin{array}{l}\text { PsA, psoriatic arthritis; RA, rheumatoid arthritis; VAS, visual analog scale; Anti- } \\
\text { CCP, anti-cyclic citrullinated peptide; IgM-RF, IgM rheumatoid factor; MRI, magnetic } \\
\text { resonance imaging; EQ-5D, EuroQol-5D. }\end{array}$} \\
\hline
\end{tabular}

calculation of all incident patients with RA in DANBIO by comparison to the Danish National Patient Registry (NPR; $85 \%$ in 2013). Since NPR is an administrative register ${ }^{3}$ in which RA diagnosis may be registered for patient contacts before the final diagnosis of the patient has been established, it cannot serve as a golden standard; however, it is the most valid nationwide register available for such comparison. Further, local medical record audits have shown that the diagnosis in DANBIO is valid. Therefore, it is assumed that the true coverage of DANBIO is higher than this estimate. ${ }^{4}$

\section{Follow-up}

At least once-a-year follow-up information is collected in DANBIO, including PROMs such as the level of function and level of pain. Disease activity, type of treatment, treatment

Table 2 Overview of the DANBIO quality indicators monitored in the Annual Clinical Quality Report

\begin{tabular}{|c|c|c|}
\hline $\begin{array}{l}\text { Indicator } \\
\text { number }\end{array}$ & Indicator title & $\begin{array}{l}\text { Standard (goal set for the } \\
\text { indicator) }\end{array}$ \\
\hline I & $\begin{array}{l}\text { Close follow-up of } \\
\text { newly diagnosed } \\
\text { patients with RA }\end{array}$ & $\begin{array}{l}\text { At least } 80 \% \text { of patients } \\
\text { registered twice during the } \\
\text { first year with disease activity } \\
\text { level }\left(\mathrm{DAS} 28^{\mathrm{a}}\right) \text {, functional } \\
\text { status }\left(\mathrm{HAQ}^{\mathrm{b}}\right) \text {, level of pain } \\
(\text { VAS painc), and treatment }\end{array}$ \\
\hline 2 & $\begin{array}{l}\text { Longitudinal follow- } \\
\text { up of all patients } \\
\text { with RA }\end{array}$ & $\begin{array}{l}\text { At least } 90 \% \text { of patients } \\
\text { registered once a year with } \\
\text { disease activity level }\left(\mathrm{DAS} 28^{\mathrm{a}}\right) \text {, } \\
\text { functional status }\left(\mathrm{HAQ}^{\mathrm{b}}\right) \text {, } \\
\text { level of pain }(\mathrm{VAS} \text { painc), and } \\
\text { treatment }\end{array}$ \\
\hline 3 & $\begin{array}{l}\text { Effective treatment } \\
\text { of all patients with } \\
\text { RA evaluated by } \\
\text { disease activity level }\end{array}$ & $\begin{array}{l}\text { Low disease activity level } \\
\left(\mathrm{DAS} 28^{\mathrm{a}}<3.2\right) \text { in at least } 66 \% \\
\text { of the registered patients }\end{array}$ \\
\hline 4 & $\begin{array}{l}\text { High functional } \\
\text { status in all patients } \\
\text { with RA }\end{array}$ & $\begin{array}{l}\text { High functional status }\left(\mathrm{HAQ}^{\mathrm{b}}\right. \\
<\mathrm{I}) \text { in at least } 60 \% \text { of the } \\
\text { registered patients }\end{array}$ \\
\hline 5 & $\begin{array}{l}\text { Effective treatment } \\
\text { of pain in all } \\
\text { patients with RA }\end{array}$ & $\begin{array}{l}\text { Low pain score (VAS painc } \\
<33 \mathrm{~mm} \text { ) in at least } 60 \% \text { of } \\
\text { the registered patients }\end{array}$ \\
\hline 6 & $\begin{array}{l}\text { High-life quality in } \\
\text { all patients with RA }\end{array}$ & $\begin{array}{l}\text { High life quality score (VAS } \\
\text { global }^{d}<33 \mathrm{~mm} \text { ) in at least } \\
60 \% \text { of the registered patients }\end{array}$ \\
\hline 7 & $\begin{array}{l}\text { Imaging by X-ray } \\
\text { performed for all } \\
\text { patients with RA } \\
\text { (of hands, wrists, } \\
\text { and feet) }\end{array}$ & $\begin{array}{l}\text { X-ray status performed in at } \\
\text { least } 80 \% \text { of the registered } \\
\text { patients at the time of } \\
\text { diagnosis and at shift between } \\
\text { types of medical treatment }\end{array}$ \\
\hline
\end{tabular}

Notes: a DAS based on a 28 joint count (tender and swollen joint counts), serum CRP, and patient global health. DAS28 $<3.2$ indicates low disease activity; DAS28 between 3.3 and 5.I, moderate disease activity; and DAS28 >5.2, high disease activity. ${ }^{\mathrm{HAQ}} \mathrm{20}$ questions in eight categories of functioning that represent a comprehensive set of functional activities. 'VAS for pain. 'VAS for patient's global. Abbreviations: CRP, C-reactive protein; DAS, disease activity score; $\mathrm{HAQ}$, Health Assessment Questionnaire; RA, rheumatoid arthritis; VAS, visual analog scale. 
effectiveness, and side effects of treatment (if any) are registered by the physician. ${ }^{5}$

Systematic monitoring of patients with RA with real-time feedback to the physician is feasible. It is documented that regular registration of disease activity for patients with RA results in improvement in disease activity, although the goal of treat to target is not achieved in a substantial proportion of patients in routine care. ${ }^{6}$

\section{Quality indicators}

The current quality indicators for RA are shown in Table 2 . The indicators include goals for whether patients are "treated to target" (ie, remission or low disease activity) by followup of patients with measurement and registration of disease activity level, functional status, pain, quality of life, and X-ray status. A standard for each indicator is set by the DANBIO steering committee and by consensus among the members of the Danish Society of Rheumatology setting goals for how large a fraction of patients who should meet the indicator criteria. The indicator results are published at country, regional, and hospital department levels in the Annual Clinical Quality Report. ${ }^{4}$ An example of supplementary results from the quality report is presented in Figure 3 that gives the number of adult rheumatologic patients initiating bDMARDs in Denmark over time and the differences in prescription pattern between geographical regions. ${ }^{4}$

\section{Examples of research}

DANBIO is used in routine care for systematic monitoring of the patients, but it is also an extensive research database.

DANBIO data have been used for research with focus on both short- and long-term evaluation of treatment responses, remission rates, and drug adherence. ${ }^{7-10}$ Furthermore, research has been performed on cancer incidence and precancerous development following treatments with biological treatment regimes, ${ }^{11,12}$ as well as on the influence of tobacco smoking on treatment response. ${ }^{13}$

More than 60 peer-reviewed articles have been published to date with the use of DANBIO data and $>170$ abstracts have been presented at international conferences and congresses.

DANBIO is easily linked to other data sources by the use of the unique personal identification number, assigned to all Danish citizens. With regulatory approval for specific research purposes, DANBIO data can be merged with ie, the NPR, the Danish Cancer Registry, or administrative registers holding socioeconomic information in Statistic Denmark.

A nationwide biobank (ie, blood and synovial fluid) associated with DANBIO has been established since 2015 through public funding.

\section{Administrative issues and funding}

DANBIO has an independent steering committee with representatives from the Danish Society of Rheumatology, DRFO

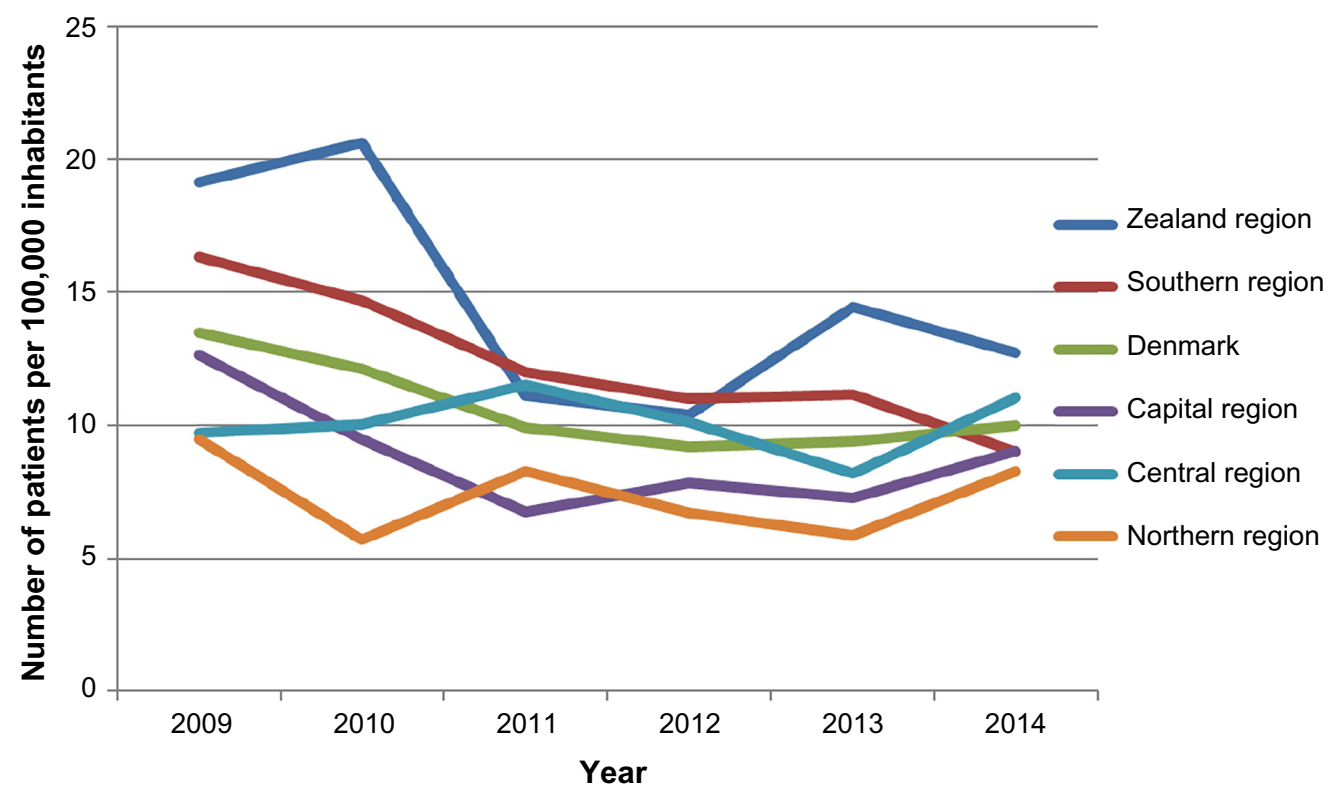

Figure 3 Number of adult rheumatologic patients initiating bDMARDs in Denmark over time across the geographical regions. Note: Reprinted with permission from DANBIO.

Abbreviation: bDMARDs, biological disease-modifying antirheumatic drugs. 
(Danske Reumatologer og Fysiurgers Organisation), Junior Rheumatologists (Yngre Reumatologer), and the hospital owners. The daily administration is handled in the DANBIO general office at Rigshospitalet, Glostrup, and is staffed by the Head of Secretariat as well as a secretary.

DANBIO has been approved as a clinical quality register by the Danish authorities - the National Board of Health and the Danish Data Protection Agency - and is sponsored by the public hospital owners (Danish Regions) under the organization of the Danish Clinical Registries - a national improvement program. The pharmaceutical companies that provide biological treatments in rheumatology contribute to the development of the information technology platform through unrestricted grants, which have been approved by the public hospital owners. The sponsors have no influence on the register setup, data collection, data analysis, or publication of results. These issues are all administered by the steering committee.

\section{Conclusion}

DANBIO serves as a powerful register for research in rheumatologic diseases and additionally as a clinical quality register with the aim of monitoring quality by the use of selected clinical indicators for patients with RA in Denmark.

The register has existed since 2000, and patients diagnosed at the hospital or at private rheumatologic clinic are registered. Since 2006, the registration, including PROMs, has been electronically registered directly into the database with the use of touch screens.

DANBIO has high nationwide coverage of patients with rheumatologic diseases and high completeness on key data variables. Data have been used for a large number of research projects and each year a National Clinical Quality Report is published.

\section{Acknowledgments}

This paper was funded by the Program for Clinical Research Infrastructure established by the Lundbeck Foundation and the Novo Nordisk Foundation and administered by the Danish Regions. DANBIO thanks the Danish Regions for supporting the register. All the Departments of Rheumatology in Demark and the private rheumatologic clinics are acknowledged for using the register. Niels Steen Krogh, Zitelab ApS, is acknowledged for the continuous technical development and support of the register.

\section{Disclosure}

The authors report no conflicts of interest in this work.

\section{References}

1. Hetland ML, Unkerskov J, Ravn T, et al. Routine database registration of biological therapy increases the reporting of adverse events twentyfold in clinical practice. First results from the Danish Database (DANBIO). Scand J Rheumatol. 2005;34:40-44.

2. Schefte DB, Hetland ML. An open-source, self-explanatory touch screen in routine care. Validity of filling in the bath measures on ankylosing spondylitis disease activity index, function index, the health assessment questionnaire and visual analogue scales in comparison with paper versions. Rheumatology. 2010;49:99-104.

3. Lynge E, Sandegaard JL, Rebolj M. The Danish national patient register Scand J Public Health Suppl. 2011;39(7 suppl):30-33.

4. DANBIO [homepage on the Internet]. Danbio's National Clinical Quality Report 2014 (Report in Danish). Available from: www.danbio-online.dk. Accessed July 01, 2015.

5. Hetland ML. DANBIO - powerful research database and electronic patient record. Rheumatology. 2011;50:69-77.

6. Hetland MH, Jensen DV, Krogh NS. Monitoring patients with rheumatoid arthritis in routine care: experiences from a treat-to-target strategy using the DANBIO registry. Clin Exp Rheumatol. 2014;32(suppl 85): 141-146.

7. Hetland ML, Christensen IJ, Tarp U, et al; All Departments of Rheumatology in Denmark. Direct comparison of treatment responses, remission rates, and drug adherence in patients with rheumatoid arthritis treated with adalimumab, etanercept, or infliximab: results from eight years of surveillance of clinical practice in the nationwide Danish DANBIO registry. Arthritis Rheum. 2010;62(1):22-32.

8. Ørnbjerg LM, Østergaard M, Bøyesen P, et al. Impact of tumour necrosis factor inhibitor treatment on radiographic progression in rheumatoid arthritis patients in clinical practice: results from the nationwide Danish DANBIO registry. Ann Rheum Dis. 2013;72(1):57-63.

9. Glintborg B, Østergaard M, Dreyer L, et al. Treatment response, drug survival, and predictors thereof in 764 patients with psoriatic arthritis treated with anti-tumor necrosis factor $\alpha$ therapy: results from the nationwide Danish DANBIO registry. Arthritis Rheum. 2011;63(2):382-390.

10. Glintborg B, Ostergaard M, Krogh NS, Dreyer L, Kristensen HL, Hetland ML. Predictors of treatment response and drug continuation in 842 patients with ankylosing spondylitis treated with anti-tumour necrosis factor: results from 8 years' surveillance in the Danish nationwide DANBIO registry. Ann Rheum Dis. 2010;69(11):2002-2008.

11. Dreyer L, Mellemkjær L, Andersen AR, et al. Incidences of overall and site specific cancers in TNF $\alpha$ inhibitor treated patients with rheumatoid arthritis and other arthritides - a follow-up study from the DANBIO registry. Ann Rheum Dis. 2013;72(1):79-82.

12. Cordtz R, Mellemkjær L, Glintborg B, Hetland ML, Dreyer L. Malignant progression of precancerous lesions of the uterine cervix following biological DMARD therapy in patients with arthritis. Ann Rheum Dis. 2015;74(7):1479-1480

13. Højgaard P, Glintborg B, Hetland ML, et al. Association between tobacco smoking and response to tumour necrosis factor $\alpha$ inhibitor treatment in psoriatic arthritis: results from the DANBIO registry. Ann Rheum Dis. 2014;74(12):2130-2136. 


\section{Publish your work in this journal}

Clinical Epidemiology is an international, peer-reviewed, open access, online journal focusing on disease and drug epidemiology, identification of risk factors and screening procedures to develop optimal preventative initiatives and programs. Specific topics include: diagnosis, prognosis, treatment, screening, prevention, risk factor modification,

Submit your manuscript here: http://www.dovepress.com/clinical-epidemiology-journal systematic reviews, risk \& safety of medical interventions, epidemiology \& biostatistical methods, and evaluation of guidelines, translational medicine, health policies \& economic evaluations. The manuscript management system is completely online and includes a very quick and fair peer-review system, which is all easy to use. 